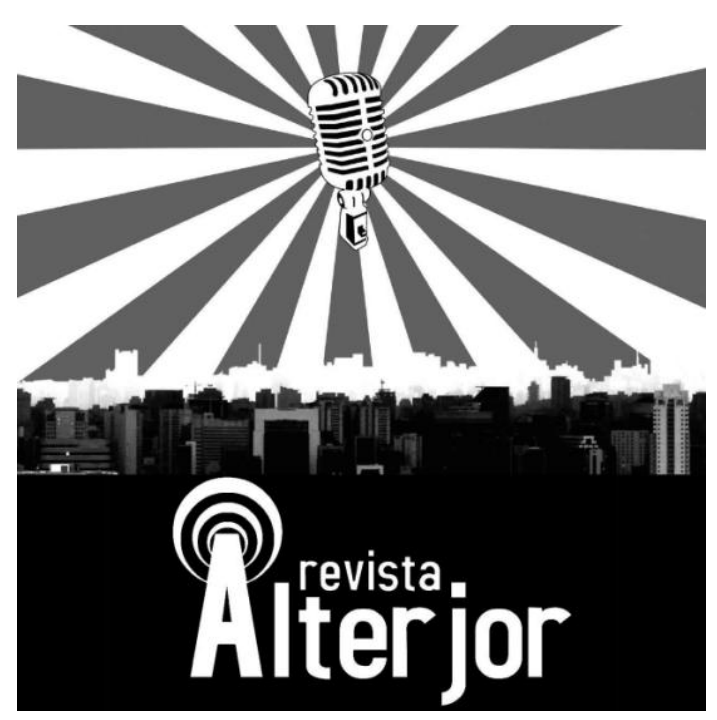

ENTREVISTA

\title{
PANDEMIA DO NOVO CORONAVÍRUS IMPÕE ISOLAMENTO SOCIAL: NOVAS PRÁTICAS NO TELEJORNALISMO REGIONAL DE BAURU, MARÍLIA E REGIÃo
}

\author{
Valquíria Aparecida Passos Kneipp ${ }^{1}$
}

RESUMO: Entrevista realizada no dia 04 de maio de 2020, com o gerente de Jornalismo da TV TEM Bauru, Marília e Região - Daniel Henrique Schafer sobre as novas práticas sociais no telejornalismo regional, em tempos do novo coronavírus. A entrevista foi realizada via internet pelo aplicativo Google Meet devido às regras de isolamento social vigentes no período da realização da mesma. Uma série de mudanças e adaptações foi adotada pelas equipes da emissora que cobre cerca de cem cidades, na região centro oeste do interior de São Paulo.

PALAVRAS-CHAVE: Telejornalismo. TV TEM. Coronavírus. Práticas Sociais. Regional.

ABSTRACT: Interview conducted on May 4, 2020, with the journalism manager of TV TEM Bauru, Marília and Region - Daniel Schafer about the new social practices in regional telejournalism, in times of the new coronavirus. The interview was conducted via the Internet using the Google Meet application due to the social isolation rules in force at the of the interview. A series of changes and adaptations was adopted by the stations' teams that cover around one hundred cities, in the central West region of the interior of São Paulo.

KEYWORDS: Telejournalism. TV TEM. Coronavirus. Social Practices. Regional.

\footnotetext{
1 Doutora em Ciências da Comunicação pela ECA - USP, Pós-Doutoranda na FAAC-UNESP e professora na Universidade Federal do Rio Grande do Norte. Contato: valquiriakneipp@yahoo.com.br
}

\section{Revista ALTERJOR}

Grupo de Estudos Alterjor: Jornalismo Popular e Alternativo (ECA-USP)

Ano 10 Volume 02 Edição $22 \quad$ Julho-Dezembro de 2020

Avenida Professor Lúcio Martins Rodrig̉ues, 443, Cidade Universitária, São Paulo, CEP: 05508-020 
VALQUÍRIA APARECIDA PASSOS KNEIPP: Como é estrutura da TV Globo nessas microrregiões no interior de São Paulo?

DANIEL SCHAFER: As afiliadas foram divididas de acordo com regiões, exatamente como você está falando. De acordo com a concessão e também de acordo com a subdivisão de uma empresa que já existia há bastante tempo. Aqui, por exemplo, onde nós estamos em Bauru é a primeira TV Globo do interior do país. A primeira unidade fora dos eixos Rio, São Paulo, Brasília, Pernambuco e Minas foi aqui em Bauru. E aí virou TV Modelo, que era uma TV que era afiliada a Globo, e hoje é a Rede Grupo TV TEM, que tem Sorocaba, Bauru, Itapetininga e Rio Preto. Como funciona? A gente segue a grade de programação da Globo, onde há espaços abertos para o telejornalismo Local, regional, a gente entra com os nossos produtos né. E aí cada empresa de acordo com a sua estrutura, tanto de pessoal, quanto técnica, é que decide quais jornais ela consegue abraçar. No caso a gente ocupa praticamente todas as grades, que a Globo permite para o jornalismo regionalizado e também para o entretenimento.

VALQUÍRIA APARECIDA PASSOS KNEIPP: A TV TEM são essas quatro praças que você mencionou. É por isso, que às vezes eu vejo aqui em Bauru umas matérias de Sorocaba?

DANIEL SCHAFER: Exatamente. Como funciona? A gente trabalha da mesma forma que a Globo trabalha. Algumas reportagens elas são produzidas aqui em Bauru, mas o assunto ele vale pra todo mundo, pra qualquer canto do país ou pra qualquer canto do estado, então, por isso, a gente compartilha muitas informações. Então muitas reportagens, que são bem produzidas, ou umas reportagens que tem um tema generalizado e tal, essas reportagens acabam sendo trocadas, entre as afiliadas Globo pra, de uma certa forma a gente ajuda a afiliada com produção né. Porque você entrega um produto pronto, e você também tem aí essa mescla de informação vinda, feita de uma outra forma, com um outro olhar e tal.

VALQUÍRIA APARECIDA PASSOS KNEIPP: Esse telejornal que eu assisto aqui em Bauru que cobre Bauru, Marília e Região. O que quer dizer essa região? Quantas cidades tem?

DANIEL SCHAFER: São cem cidades. 


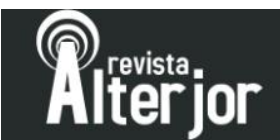

VALQUÍRIA APARECIDA PASSOS KNEIPP: Como você disse a emissora cobre todos os horários que Globo disponibiliza. A produção é só jornalismo?

DANIEL SCHAFER: A TV TEM a rede TEM produza jornalismo e entretenimento. O entretenimento é produzido pela equipe do entretenimento, que é separado do jornalismo e fica em Sorocaba.

VALQUÍRIA APARECIDA PASSOS KNEIPP: Aqueles programas do fim de semana?

DANIEL SCHAFER: Isso mesmo. Sábado e domingo. No domingo tem o Nosso Campo e no sábado tem o Revista de Sábado e o De ponta a Ponta.

VALQUÍRIA APARECIDA PASSOS KNEIPP: Você tem ideia de quantas horas de jornalismo são produzidas diária o semanalmente?

DANIEL SCHAFER: Olha diariamente deve dar umas duas horas e dez minutos mais ou menos, porque tem aquelas entradas ao vivo na programação, que a gente também faz. Deve dar mais ou menos isso diariamente. Semanalmente são seis dias da semana, então umas 14 a 15 horas de jornalismo regional.

VALQUÍRIA APARECIDA PASSOS KNEIPP: Nesse período de pandemia coronavírus, quais as mudanças que ocorreram na forma de produção de conteúdo jornalístico?

DANIEL SCHAFER: Olha a nossa rotina mudou muito desde que a pandemia foi anunciada e nós estamos bem próximos do epicentro no país, que é a capital paulista. Desde que isso começou a acontecer, a empresa tomou várias atitudes de preservação dos profissionais, e também de preservação das pessoas que a gente tem contato. Então nós fomos divididos em grupos, por exemplo, a equipe da manhã não tem contato com a equipe da tarde, justamente para o caso de alguém se contaminar, não contaminar o colega do outro turno. As pessoas que são do grupo de risco - idosos ou que já tem alguma doença crônica foram retiradas do trabalho. Estão home office ou em férias. Enfim mudou a nossa rotina de higiene né. A higiene tanto dos equipamentos, quanto

Revista ALTERJOR

Grupo de Estudos Alterjor: Jornalismo Popular e Alternativo (ECA-USP)

Ano 10 Volume 02 Edição $22 \quad$ Julho- Dezembro de 2020

Avenida Professor Lúcio Martins Rodrig̉ues, 443, Cidade Universitária, São Paulo, CEP: 05508-020 


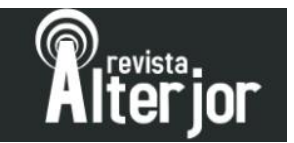

pessoal é a cada instante. Está todo mundo de máscara, usando álcool em gel a todo instante. Os equipamentos são higienizados a cada instante, quando troca de pessoa são higienizados também. A redação passou por uma higienização diária, várias vezes ao dia. Enfim uma rotina que mudou muito. Isso mudou bastante a nossa rotina.

VALQUÍRIA APARECIDA PASSOS KNEIPP: A equipe de reportagem está usando dois microfones, e quebra uma regra clássica do telejornalismo - que o entrevistado não pega no microfone. Como é que está resolvendo essa questão?

DANIEL SCHAFER: Quando a gente começou a viver a pandemia. Imagina assim, eu tenho de telejornalismo 13 anos. Eu me considero um cara muito jovem na profissão ainda. Eu sei que tem gente que tem muito mais experiência que eu. Mas assim, em todo esse tempo, eu nunca imaginei que eu ia viver uma pandemia. Eu acho que está sendo um momento histórico pra qualquer jornalista. A gente é jornalista pela sangue, eu falo que o glamour que todo mundo vê na televisão, por exemplo, que é onde eu trabalho, ele não existe. Nós trabalhamos pelo sangue. A gente trabalha por garra, por vontade. Isso todo mundo sabe nós não somos super bem remunerados como qualquer outro órgão de imprensa. Nós ganhamos o teto do mercado e somos batalhadores da mesma forma. Eu acho que esse momento que gente está vivendo é histórico porque a gente vai ficar pra história na cobertura de uma pandemia que atingiu a gente. E quando chegou essa pandemia e começou toda essa questão da higienização, a gente percebeu que a gente precisava manter o distanciamento do entrevistado, que é uma coisa complicada porque quando a gente vai entrevistar alguém, a gente chega, a gente sempre tenta interagir com a pessoa justamente para fazer com que ela fique a vontade, para ela poder falar com a gente, pra ela transmitir informações com mais vontade mesmo, liberdade. $\mathrm{E}$ isso criou uma barreira, porque agora a gente tem uma regra de distanciamento. $\mathrm{O}$ distanciamento por si só já é algo complicado porque cria uma certa barreira, que antigamente a gente tentava quebra porque, "ah olha o repórter da televisão" já existia uma coisa assim. Então a gente se aproximava das pessoas justamente pra tentar quebrar isso. E agora não é o inverso, a gente tem que ficar longe. E aí o lance do microfone foi uma grande luta porque até a gente conseguir encaixar, que o ideal seria ele estar com o microfone dele, a gente tentou lapela, a gente tentou várias coisa pra dar certo um microfone de mão para ele e um microfone de mão pro repórter.

VALQUÍRIA APARECIDA PASSOS KNEIPP: Vocês tem alguma equipe trabalhando em home office? 
DANIEL SCHAFER/LUCIANO VICTOR BARROS MALULY: A gente só não tem hoje equipe de reportagem atuando em home office, porque nós não temos muitas equipes. Nós temos seis equipes de reportagem e nessas seis duas são compostas por apresentadores. Então eu tenho quatro equipes de reportagem, só de repórter e repórter cinematográfico. Então eu não tinha condições estruturais de ter uma equipe em casa. Só que é assim, se for necessário, se o repórter precisar de um momento em casa, por isolamento seja qual for, a gente pode ter essa opção né.

VALQUÍRIA APARECIDA PASSOS KNEIPP: Observando as redes sociais da emissora percebi que não tem distribuição de material jornalístico. Qual é a estratégia da TV TEM?

DANIEL SCHAFER: eu não tenho como te responder claramente sobre isso, porque não é o meu setor. Tem um setor específico das redes sociais da TV. Mas o que eu sei é que TV está atuando nas plataformas aí Facebook, Instagram, principalmente. Essas duas redes sociais, alí eles tem um trabalho de divulgação de n produtos da TV. Mas eu não consigo responder essa pergunta claramente, porque não é do meu setor eu não tenho nem acesso a isso pra dizer.

VALQUÍRIA APARECIDA PASSOS KNEIPP: Não existe uma estratégia casado das redes sociais, com jornalismo e não tem conteúdo jornalístico nas redes sociais?

DANIEL SCHAFER: Se o conteúdo jornalístico é utilizado ou não, eu não consigo te dizer. Eu sei assim, que muita coisa que a gente faz, e que às vezes chama maia atenção nas redes sociais. Esse tipo de situação é que eles aproveitam mais.

VALQUÍRIA APARECIDA PASSOS KNEIPP: Existe a possibilidade de uma matéria ir para as redes sociais antes de ser exibida pela TV?

DANIEL SCHAFER: O que é reportagem a gente usa no telejornal e às vezes algumas coisas vão para o G1. O que pode acontecer e da equipe que está fazendo a matéria em um lugar mandar material para o G1, e o G1 publicar algumas coisas. Esse trabalho é bem parceiro assim. A equipe de reportagem que está em algum lugar, ela pode mandar conteúdo para o G1 e o G1 publicar a matéria. Isso acontece. É um trabalho colaborativo. É claro que algumas matérias que são exclusivas, por exemplo, uma

Revista ALTERJOR

Grupo de Estudos Alterjor: Jornalismo Popular e Alternativo (ECA-USP)

Ano 10 Volume 02 Edição $22 \quad$ Julho- Dezembro de 2020

Avenida Professor Lúcio Martins Rodrig̉ues, 443, Cidade Universitária, São Paulo, CEP: 05508-020 
denuncia que a TV esteja apurando, a TV vai levar a fundo e só vai ar no G1 depois que TV publicar. E assim vice versa, se o G1 estiver com alguma pauta que for exclusiva deles, e for uma denuncia, só vai ao ar na TV depois que G1 publicar. Mas tem material do dia a dia que a gente faz os dois e vai compartilhando.

VALQUÍRIA APARECIDA PASSOS KNEIPP: O conteúdo do telejornal ainda não está compartilhado pelas redes sociais?

DANIEL SCHAFER: A relação maior é com o G1. Eu acho que a TV está mais preocupada hoje com a estrutura de plataforma de notícias mesmo que é o G1. A plataforma de rede social ela utiliza mesmo como interação de rede social mesmo.

VALQUÍRIA APARECIDA PASSOS KNEIPP: Com a cultura da participação, o telespectador envia vídeos engraçados ou exista também uma participação no sentido de poder gerar pautas também?

DANIEL SCHAFER: Chegam pautas sim. O grande lance desses últimos anos do telejornalismo, acredito que desde que o WhatsApp se consagrou como grande mecanismo de comunicação mudou muito a participação das pessoas. As pessoas participam ativamente assim, agora nesse período de pandemia está bem complicado, porque o jornal está praticamente monotemático. É um tema coronavírus, quando muda é dengue. Sabe é pela necessidade do momento, da quantidade de informações que isso está gerando. Mas gente várias situações como, por exemplo, a gente criou um quadro dentro do jornal, que chama cantinho do WhatsApp, que é onde as pessoas mandam as denuncias delas em vídeo, em fotos e a gente põe no ar. Às vezes é a própria pessoa narrando, falando olha "isso aqui está assim", e às vezes uma sugestão que chega vale uma reportagem, vale mandar uma equipe, e a gente manda a equipe lá e fala quando vai chamar a reportagem na cabeça: "esta reportagem foi sugerida por um telespectador". Hoje eu acho que o telespectador ele é muito ativo no jornal. E também é muito julgador assim. A gente tem o telejornal no ar, e o telespectador julgando em tempo real. O jornal acaba e a gente tem analistas de tudo, analistas de roupa, analistas de cabelo, analistas de português, analistas de tudo.

VALQUÍRIA APARECIDA PASSOS KNEIPP: $E$ vocês não respondem a esses analistas de tudo?

Revista ALTERJOR

Grupo de Estudos Alterjor:Jornalismo Popular e Alternativo (ECA-USP)

Ano 10 Volume 02 Edição $22 \quad$ Juho- Dezembro de 2020

Avenida Professor Lúcio Martins Rodrig̉ues, 443, Cidade Universitária, São Paulo, CEP: 05508-020 


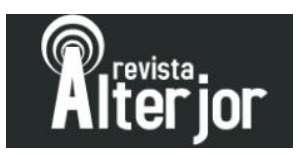

DANIEL SCHAFER: Até que conversa ela existe. A gente tem um produtor que sempre fica com o WhatsApp e ele sempre. É claro que a gente não consegue responder tudo de bate pronto, porque tem dia que em um telejornal chegam duzentas mensagens, em minutos. Então, assim é desumano achar que a gente vai conseguir responder tudo tão rapidamente. Mas tem um produtor que ele fica responsável. Ao longo do dia de trabalho tem sempre um produtor com o WhatsApp. Não é uma única pessoa, ela vai mudando de mãos. E esse produtor ele faz a filtragem das coisas, conversa com as pessoas, ele já faz a checagem com ela, faz as perguntas básicas para ver se aquilo é realmente pra gente, ou se a pessoa só precisa de uma ajuda de uma orientação. Isso tudo é feito por um produtor que vai acompanhando o WhatsApp.

\section{VALQUÍRIA APARECIDA PASSOS KNEIPP: Existe uma organização por editorias e regiões no telejornal? Como é pensada a estrutura de um telejornal?}

DANIEL SCHAFER: Não existe uma regra assim que defina qual é estratégia usada para fechar ou pra desenhar o formato que aquele telejornal vai ter. o espelho do jornal que é a sequencia de reportagens que vem ao ar. A gente não tem uma regra para definir isso. Cada jornal tem um editor chefe. Então já começa por aí que já tem uma pessoa diferente que da a impressão dela, de acordo com o que ela acha que segue melhor naquela estruturação de reportagem, o que vem depois do que? então já existe aí um filtro diferenciado porque uma coisa é o editor chefe do Jornal da manhã, outra coisa é o editor chefe do jornal do meio dia e outra coisa é a editora chefe do jornal da noite. Cada um com uma cabeça, cada um com uma pegada vamos assim dizer. Então isso influencia é claro, na forma com que essas notícias são distribuídas. E isso também a ver com pegada da notícia, também tem a ver com a influencia do que a gente tem de conteúdo, por exemplo, tem três reportagens sobre esse assunto, então vamos agrupar elas aqui, nesse bloco, deixa o esporte pra baixo. Ah não tem uma matéria mais fofinha, então deixa ela pra terminar o jornal e põe o esporte mais pra cima. Então tudo depende desse tipo de análise. E isso é feito no dia a dia. A gente costuma dizer que cada jornal é de um eito e que cada dia é de um jeito, e nunca vai ter uma regra.

VALQUÍRIA APARECIDA PASSOS KNEIPP: Como que é conviver com as normas da Globo relativas ao uso de redes sociais para repórteres e apresentadores?

DANIEL SCHAFER: Eu acho tranquilo. São recomendações como qualquer empresa. Imagina a gente, o nosso contrato é um contrato de imagem. Então a ideia é que você 


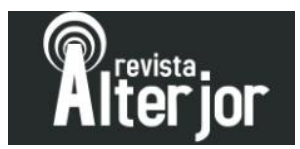

não vincule a sua imagem com nenhuma marca, que é algo sensato para quem é jornalista de televisão.

VALQUÍRIA APARECIDA PASSOS KNEIPP: Como é a relação da emissora com a editoria Fato ou Fake do G1?

DANIEL SCHAFER: Toda rede ela passa para o G1 local, que passa para o nacional, que é responsável pela editoria. Mas agente, quando é algo local, por exemplo, há uma semana nós tivemos em Marília uma fake News que informou que iria estar distribuindo cestas básicas em um bairro, num determinado lugar, e centenas de pessoas foram pra lá, uma fila gigantesca e era uma mentira. Então quando é algo regional, local, a gente pega e põe no jornal para desmentir. Aí a gente traz a notícia falsa e desmente-a no ar. Agora quando é algo que está circulando pelas redes sociais, já é fake News de internet que chegou aqui. Aí a gente passa pro G1, e o G1 que desmistifica no Fato ou Fake.

VALQUÍRIA APARECIDA PASSOS KNEIPP: A TV TEM está usando a internet para fazer entrevista online para reportagens e para o ao vivo?

DANIEL SCHAFER: A gente utiliza sim, a gente só não utiliza dentro do jornal, porque a gente os nossos repórteres na rua com os nossos vivos, com todos os sinais de vivo pela internet, então a gente não está utilizando Skype por isso. Mas, por exemplo, a gente está utilizando o Skype e todas as outras ferramentas de vídeo como Zoom. HangOuts, WhatsApp para fazer entrevistas e fechar as reportagens, que muitas vezes não precisam nem de contato entre as pessoas né.

VALQUÍRIA APARECIDA PASSOS KNEIPP: A emissora trabalha com equipes de reportagem tradicional e também com os videorrepórteres?

DANIEL SCHAFER: Não aqui na nossa área de cobertura de Bauru nós não temos vídeo repórter.

VALQUÍRIA APARECIDA PASSOS KNEIPP: A produção das reportagens é feita coletivamente ou existem as funções definidas?

Revista ALTERJOR

Grupo de Estudos Alterjor:Jornalismo Popular e Alternativo (ECA-USP)

Ano 10 Volume 02 Edição $22 \quad$ Juho- Dezembro de 2020

Avenida Professor Lúcio Martins Rodrig̉ues, 443, Cidade Universitária, São Paulo, CEP: 05508-020 


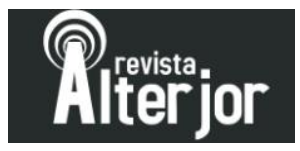

DANIEL SCHAFER: Aqui a gente mantém a estrutura de redação. Tem produtor, editores, repórteres, cinegrafistas, editores de VT. Nós temos ainda produtores produzindo tudo.

VALQUÍRIA APARECIDA PASSOS KNEIPP: $O$ que pode ser melhorado dentro da cobertura jornalística realizada pela emissora?

DANIEL SCHAFER: Eu acho assim, que o ponto positivo do que a gente tem vivido e tem a ver com o que eu acho que tem que melhorar. O ponto positivo é que a gente está cada vez mais multi. Todo mundo faz tudo e a gente está cada vez mais online. Digo o jornal, ele cada vez mais a gente está trazendo a notícia mais quente ao vivo. Menos reportagens e mais ao vivo dentro dos telejornais. E isso eu acho que também é algo que deve ser melhorado. A gente precisa ter cada vez mais participações ao vivo, seja com repórteres ou só entrevistados sendo questionados pelo apresentador, e menos reportagens gravadas. Porque eu acho que isso, a reportagem quando ela entra no ar, ela um pouco que quebra o andamento do jornal, e acho que isso afeta um pouco a audiência e afeta um pouco o telespectador. Então acho que as estruturas de vivo, hoje em dia interessam muito mais do que as reportagens gravadas e editadas. O grande lance é ver o repórter onde ele está. 